\title{
Volunteer beach cleanups: civic environmental stewardship combating global plastic pollution
}

\author{
Bethany Jorgensen ${ }^{1,3}$. Marianne Krasny ${ }^{1} \cdot$ Juan Baztan $^{2,3}$
}

Received: 1 December 2019 / Accepted: 16 July 2020

(c) Springer Japan KK, part of Springer Nature 2020

\begin{abstract}
Marine litter, the majority of which is plastic, is one of the most pressing global environmental challenges impacting the planet. One way coastal communities respond to this challenge is through the environmental stewardship practice of volunteer beach cleanups. Beyond providing temporarily cleaner local beaches, how might these beach cleanups have broader impacts in the global struggle against plastic pollution? Using the lenses of environmental stewardship and civic ecology, we conducted a content analysis of primary source materials created by 50 groups involved in volunteer beach cleanups. We collected data on the scale at which groups coordinate volunteer beach cleanups, the roles they play in conducting these cleanups, how they interact with other volunteer beach cleanup groups, and the other forms of stewardship they conduct, if any. Within our sample, we identified groups coordinating volunteer beach cleanups at five geographic scales: local, sub-national, national, multi-national, and global. Within the groups operating at each scale, we found groups conducting environmental stewardship in the forms of education, advocacy, research, and monitoring in addition to their conservation work through beach cleanups. Our findings demonstrate that groups branch out their impacts by combining different forms of environmental stewardship targeting plastic pollution, and they collaborate to scale up their actions in ways that contribute to plastic pollution governance. Connecting these findings with the literature on the broader impacts of civic ecology practices allows us to theorize how volunteer beach cleanup groups branch out and scale up their efforts to weave a global net of ocean stewardship.
\end{abstract}

Keywords Marine litter $\cdot$ Civic ecology $\cdot$ Beach cleans $\cdot$ Ocean stewardship

Bethany Jorgensen and Juan Baztan: Members of Marine Sciences for Society.

Handled by Graham Epstein, University of Waterloo Faculty of Environment, Canada.

Electronic supplementary material The online version of this article (https://doi.org/10.1007/s11625-020-00841-7) contains supplementary material, which is available to authorized users.

Bethany Jorgensen

bj265@ cornell.edu

1 Civic Ecology Lab, Department of Natural Resources, Cornell University, 144 East Ave., Ithaca, NY 14853, USA

2 Research Centre

Cultures-Environnements-Arctique-Représentations-Climat (CEARC), Université de Versailles-Saint-Quentin-en-Yveli nes, UVSQ, 11 Boulevard d'Alembert, 78280 Guyancourt, France

3 Marine Sciences For Society, Barcelona, Spain

\section{Introduction}

Marine litter is one of the most pressing global environmental challenges impacting the planet (Galgani et al. 2015; Topçu et al. 2013; Thiel et al. 2013; Barnes et al. 2009). The majority of marine litter is plastic (Derraik 2002), whose persistence in the environment, dispersability, mismanagement, and increasing production have led to extensive plastic pollution throughout the biosphere (see Baztan et al. 2017; Bergmann et al. 2019; Wagner et al. 2018; Van Sebille et al. 2015; Cózar et al. 2014). This includes oceans and coastlines (Jambeck et al. 2015; Thompson et al. 2009; Law and Thompson 2014). The scientific community's concern about plastic pollution is reflected in the growing number of peer-reviewed publications and increasing participation in academic conferences (e.g., international MICRO 2018 conference on microplastics; Baztan et al. 2016; Baztan et al. 2018). The plastic pollution crisis is also receiving more attention in media (Henderson and Green 2020), government 
policies (Xanthos and Walker 2017), and private sector actions (Stafford and Jones 2019). Further, members of civil society are taking actions ranging from local volunteer beach cleanups to large-scale global cleanup campaigns. For example, over 1 million volunteers from 122 countries participated in the 2018 International Coastal Cleanup (Ocean Conservancy 2019), and according to the Let's Do It! Foundation (2018), their 2018 "World Cleanup Day" engaged 13 million participants in 144 countries. Smaller-scale volunteer beach cleanup efforts regularly take place in coastal communities around the world; however, their impacts remain understudied.

Given the enormity of global plastic pollution, how might small-scale volunteer beach cleanups, even when coordinated globally, be meaningful? Our study addresses this question using the lens of civic ecology, which focuses on small-scale, grassroots environmental stewardship practices that can branch out and scale up to have broader impacts (Krasny and Tidball 2015; Krasny 2018). We use primary source materials produced by volunteer beach cleanup groups in this initial exploration of the scope, approaches, and collaborations entailed in volunteer beach cleanups that may indicate scaling up impacts beyond local beaches. We also identify additional forms of environmental stewardship conducted by these groups to theorize how branching out through other stewardship practices may broaden the impact of beach cleanup groups' efforts to eliminate plastic pollution.

Our findings contribute to the literature on civic ecology and environmental stewardship by revealing a global net of volunteer beach cleanup efforts conducted in tandem with other stewardship endeavors. We conclude by placing these findings in the context of their implications for understanding the theoretical pathways through which civic ecology practices have impacts beyond their local communities.

\section{Environmental stewardship and civic ecology}

Volunteer beach cleanups remove marine litter after it has entered the environment rather than preempting plastic pollution by targeting the source and reducing plastic production. Because of this, they have been accused of being palliative actions, ineffective at addressing plastic pollution (De Wolff 2017; Nelms et al. 2016; Williams et al. 2016; Rees and Pond 1995). However, the literature on environmental stewardship and civic ecology suggests volunteer activities such as beach cleanups entail complex processes for reinforcing beneficial civic structures and ecological systems, which can lead to adaptive environmental governance (Gunderson et al. 2018; Krasny and Tidball 2015). Such processes include enhancing participants' agency (Haywood et al. 2016), collaborative knowledge making (Silva and Ramirez 2018; Silva 2017; Silva and Krasny 2016), transformative learning (Chaves and Wals 2018), social-ecological learning and community resilience (Smith et al. 2016; Chan et al. 2015), culture building (Krasny 2018; Andrews and Edwards 2005), sense of place (Enqvist et al. 2019; Haywood et al. 2016), network building for environmental governance (Murphy et al. 2019; Romolini et al. 2016; Svendsen and Campbell 2008; Andrews and Edwards 2005), and social movement building (Abhyankar and Krasny 2018; Andrews and Edwards 2005). Our study is one step in understanding possible connections between volunteer beach cleanups and these potential spillover effects (Nilsson et al. 2017; Thøgersen and Crompton 2009).

In the face of global environmental challenges such as plastic pollution, environmental stewardship actions and initiatives enable citizens to act on environmental concerns locally using their own knowledge and expertise (Bennett et al. 2018). Environmental stewardship occurs when individuals working independently, in local groups, or in regional networks, leverage their capacity and motivation to use various "approaches, activities, behaviors, and technologies" (Bennett et al. 2018, p. 606) to conserve, restore, manage, monitor, advocate for, and/or educate about the environment (Fisher et al. 2012; Bennett et al. 2018). Such stewardship can vary from a single action to long-term initiatives and encompass improving or protecting water, land, and air quality (Svendsen et al. 2016). Through their efforts, stewardship groups endeavor to construct the social infrastructure required for sustaining environmental practices, such as city- or watershed-wide governance networks (Connolly et al. 2014; Romolini et al. 2016). Wolf et al. (2013) found that participants in environmental stewardship are motivated to participate for the social benefits derived through these practices such as community building, citizen engagement, and concern for community, which are as important as the perceived ecological benefits. Because environmental stewardship links local quality-of-life and environmental concerns, it has the potential to benefit participants, their communities, and the environment.

Environmental stewardship efforts tend to be opportunistic and focused on specific projects or sites. This poses a challenge for comprehensively assessing their cumulative effects; long-term monitoring is rare and stewardship impacts are poorly understood (Wolf et al. 2013). To address this gap, Krasny (2018) edited a collection of case studies focusing on broader impacts of civic ecology practices, defined as volunteer, hands-on, self-organized environmental stewardship (Krasny and Tidball 2012). Drawing from the 12 case study chapters, Krasny (2018) theorizes three pathways through which the impacts of civic ecology practices extend beyond their local scale of implementation: knowledge building, culture building, and movement building.

According to Krasny (2018), knowledge building in civic ecology practices occurs when groups engage in research 
and monitoring as part of their stewardship practice (e.g., through citizen science). Practitioners also learn with each other through the process of engaging in a civic ecology practice (Smith et al. 2016). For example, tree stewards not only learn how to plant trees, but also how to maintain and monitor tree health and in so doing engage in tacit knowledge making (Silva 2017). Through monitoring, other data collection, and investigating research questions, environmental stewards extend the impact of their civic ecology practices by being better able to assess, advocate for, and communicate about their stewardship to other community members, researchers, and policy makers (Krasny 2018; Silva and Krasny 2016).

Culture building takes place as a civic ecology practice becomes a regular, visible occurrence in a community, tapping into existing social norms, attitudes, and values (Krasny 2018). For example, members of the Iranian litter cleanup group Nature Cleaners describe their work as farhang-sazi, a model of culture building that shifts behavior through appeals to deep cultural values. Nature Cleaners emphasizes the cultural and religious value of cleanliness (Kassam et al. 2018) as part of their call to keep the environment free of litter. While initially the scale of "community" for a civic ecology practice may be contained within the local environment, some civic ecology practitioners find ways to extend their reach through linking with others, such as using social media or participating in Massive Open Online Courses (MOOCs) (Krasny, unpublished observations), to form communities of practice whose members share common interests and deepen their understanding and expertise through their interactions over time (Wenger et al. 2002).

Movement building (Krasny 2018) occurs when civic ecology practices contribute to governance networks (Romolini et al. 2016; Svendsen et al. 2016; Connolly et al. 2014), and to social movements such as urban agriculture, civic environmentalism, and environmental justice. A civic ecology group in India called The Ugly Indian catalyzes movement building by connecting people in multiple places via social media, and conducting strategically targeted litter cleanups or "spot-fixes" (Abhyankar and Krasny 2018). Their tag-line, "We are all Ugly Indians," implicates everyone as responsible for keeping public areas clean and reflects the collective action framing (Benford and Snow 2000) they use to mobilize volunteers. They encourage similar spot-fix groups to form in cities across India while protecting their own organizational identity by not allowing new groups to use "The Ugly Indian" in their name (Abhyankar and Krasny 2018).

Krasny's (2018) three pathways align with theory from the literature on scaling up collective action. For example, Jagers et al. (2019) suggest that addressing complex, larger-scale collective action problems, where actors cannot directly monitor each other's actions or anticipate other's decisions, requires "cognitive, coordinative, normative, and informational guidance" (p. 3). While they recommend this come from third-party organizations, we see parallels between the need for "cognitive" and "informational" guidance and the pathway of knowledge building; while "normative" guidance suggests a parallel to culture building. These marshaled together, according to Jagers et al. (2019), contribute to larger-scale collective action, or what Krasny (2018) refers to as the movement-building pathway.

Similarly, from the social movement literature, Oliver and Myers (2003) describe social movements as consisting of "smaller campaigns in particular localities or involving particular issues. These smaller campaigns usually arise either from a burst of repeated actions by one group or in one locality, or the diffusion of a particular movement issue, frame or tactic between groups or localities" (p. 175-176). They outline three models for distinct processes within social movements that support Krasny's (2018) three pathways for scaling up civic ecology practices. The first is the flow of information, which aligns with knowledge building; the second is the flow of influence, as a parallel to culture building; the third is the construction of joint action, which resonates with movement building.

\section{Environmental stewardship across scales}

Environmental stewardship scholars have studied the organizational structures and characteristics of urban environmental stewardship groups (Svendsen and Campbell 2008; Fisher et al. 2012) and the ways in which stewardship groups are networked across scales ranging from the local level of a neighborhood to regional watershed (Connolly et al. 2014; Romolini et al. 2016, 2013). They have developed tools like the US. Forest Service's Stewardship Mapping and Assessment Project database (Svendsen et al. 2016). For example, Connolly et al. (2014) found stewardship groups in New York City serves as bridges to other civic and government groups and work alongside local planners and decisionmakers to form hybrid environmental governance systems, whose activities extend from civic participation in neighborhoods to city-wide decision-making.

While acknowledging stewardship can range across spatial scales, the trend in environmental stewardship scholarship is to apply city-, regional- or resource-based scales, such as a watershed, as the largest scope for analyzing stewardship practices, groups and networks (Bennett et al. 2018; Svendsen et al. 2016; Romolini et al. 2016; Fisher et al. 2012; Wolf et al. 2013). In emphasizing the role of smallerscale stewardship, environmental stewardship scholars have yet to conceptualize global environmental stewardship as may be necessary for addressing larger-scale collective action problems such as global plastic pollution. However, here the work of sustainability governance scholars provides 
insight into how environmental stewardship practices and the groups leading them have a role in responding to global environmental challenges. For example, in her work on polycentric governance as a means to manage the collective action problem (Ostrom et al. 1961) of climate change by linking independent loci of decision-making across various levels of jurisdiction, Ostrom (2010) argues for including small- and medium-scale governance units along with the global ones so that multiple benefits are derived from diverse actions at different scales. This echoes work on Earth Stewardship (Power and Chapin 2009; Chapin et al. 2011; Ogden et al., 2013) and global governance for environmental sustainability (Steffen et al. 2011), which posits that actions addressing larger-scale environmental issues should be composed of multi-level adaptive governance systems (Folke et al. 2011). In a polycentric governance system for plastic pollution, volunteer beach cleanup groups would collaborate with other organizations and governmental agencies at scales ranging from local to global.

\section{Volunteer beach cleanups}

Volunteer beach cleanups address globally circulating pollution, which gives them and the marine litter they focus on complex scalar and temporal dimensions. The practice of removing marine litter from a beach is necessarily local; however, participants often are cleaning up garbage left behind by beach visitors or washed ashore by ocean currents, meaning the marine litter they remove could come from halfway around the world (Lavers and Bond 2017). Relative to the temporal scale, beach cleaning tends to be a Sisyphean task repeated regularly due to recurring seasonal patterns of marine litter accumulation. Unlike civic ecology practices focused on helping things grow, such as tree planting (Fisher et al. 2015), community gardening (Silva and Krasny 2016), or dune restoration (Smith et al. 2016), beach cleanups focus on removing undesirable and even disgusting material. Similar to these other practices, however, volunteer beach cleanups enact "alternative trajectories and futures" (Gunderson et al. 2018, p. 158). They are performatively normative (Butler 2010) in that they materially, even if momentarily, reflect participants' hopes for how their community_and the biosphere_-should be. By removing marine litter from the beach, participants make performative and ethical statements about what belongs on the beach and what does not, who is responsible for and capable of making these decisions, and how they should be carried out once made. Additionally, beach cleanups can be viewed as purification rituals (Douglas 2003), removing material identified as litter in efforts to restore the aesthetic appearance of the beach and improve the coastal environment. Hawkins (2006) argues that litter has come to be represented as morally unsettling, "evidence of the collapse of civic obligation" (p. 30). By joining with others to face societal disregard for the environment and incivility in the form of marine litter, volunteer beach cleaners reaffirm the importance of caring for the environment as social and ecological members of our biosphere community. Removing marine litter from beaches becomes a form of taking action against plastic pollution and of enacting a vision of plastic-free oceans and beaches.

One concern about framing volunteer beach cleanups as a solution to the plastic pollution crisis is that such framing shifts the "narrative of responsibilization" (Littler 2013, quoted by Braun and Traore 2015, p. 883) away from industry and government to consumers and civil society. For example, governments may encourage volunteer beach cleanups since they provide free labor in lieu of implementing costly measures to remove plastics from the environment or improve waste management (Newman et al. 2015; UNEP and GRID-Arendal 2016). Industry actors have actively controlled the narrative of responsibilization for plastic and other pollution by placing blame on consumers and civil society through marketing and other strategies. For example, in 1953, the NGO Keep America Beautiful was established by the packaging industry (Elmore 2014) to "preempt legal restrictions on disposable goods, namely packaging" (Rogers 2009, p. 232), and its public relations campaign (Rogers 2009; MacBride 2011; Elmore 2014) was so successful that it is used to illustrate the power of social norms messages in promoting pro-environmental behavior (cf. Cialdini et al. 1991). Moreover, Keep America Beautiful provides one of the earliest examples of industry pioneering a new form of greenwashing called "astroturfing," defined as "corporatefinanced political action campaigns made to look like grassroots initiatives" (Elmore 2014, p. 234). Such greenwashing efforts circumscribe discussions related to corporate actors limiting how much plastic they produce and require for their products, and their role in ensuring it does not become pollution (Elmore 2014; MacBride 2011). In fact, industry players support volunteer beach cleanups through partnerships (e.g., Coca-Cola is the leading sponsor of the Ocean Conservancy's International Coastal Cleanup). Whereas the nonprofit Alliance to End Plastic Waste, launched in 2019, has pledged 1 billion USD over the next 5 years toward eliminating plastic pollution (Harvey 2019), some alliance members such as Shell and ExxonMobil have invested 180 billion USD in plastic production since 2011 (Laville 2019; Kistler and Muffett 2019).

This poses the risk of volunteer beach cleanups becoming co-opted into MacBride's (2011) definition of "busy-ness," or situations where there is "a great deal of activity, the appearance of progress and improvement, but an underlying stasis or, worse, a net growth in the material dimensions of the solid-waste problems that such solutions set out to address in the first place" (p. 5). This dynamic maintains the status quo through helping people feel they are making 
a positive difference when they are not, and their energies would be more effectively applied elsewhere. In this way, volunteer beach cleanups may be an eddy redirecting civic energy away from direct political action. Yet the space for civic engagement opened by such practices can create or reinforce the social infrastructures and dynamics (Fisher et al. 2012; Wolf et al. 2013; Kempton et al. 2001) needed to hold policy makers and industry accountable for plastic pollution.

Our study expands understanding of environmental stewardship by exploring if and how different forms of stewardship are combined through the work of groups taking action against plastic pollution, and how these groups' efforts are interwoven with each other to remove plastic pollution from the world's oceans, waterways, and coastal zones. By examining these aspects of beach cleanup group practices, we theorize how volunteer beach cleanup groups branch out and scale up their impacts from local implementation to achieve global ocean stewardship. In this way, our study broadens the geographic scale of analysis for environmental stewardship to extend to the global, and explores how volunteer beach cleanups function as examples of civic ecology working within and across geographic and socio-political scales. We use the socio-political scale of action (e.g., local, subnational, national, multi-national, or global) for each group in our sample as the primary lens through which we categorize the groups, and compare the scope of their actions, their roles in coordinating and conducting cleanups, how they interact with each other, and the other forms of stewardship they conduct. Doing so enables an understanding of how volunteer beach cleanup groups might do more than clean beaches to fight plastic pollution.

For example, indicators of impacts scaling up could include local and global volunteer beach cleanup groups collaborating on campaigns. Indicators of impacts branching out could include volunteer beach cleanup groups conducting additional stewardship actions, including research, monitoring, management, policy advocacy, and education (Fisher et al. 2012). We use our findings to build on Krasny's (2018) three pathways for scaling up civic ecology practices through knowledge-, culture-, and movement building, and theorize how the impacts of beach cleanup group actions may extend beyond briefly cleaner beaches to weave nets of global ocean stewardship.

\section{Methods}

To answer our question about the broader impacts of volunteer beach cleanup groups in the fight against global plastic pollution, we identified how their cleanup actions are conducted and what other kinds of environmental stewardship actions these groups take. We performed a content analysis of primary source materials created by volunteer beach cleanup groups as an initial exploration of what a sample of these groups do and how they operate. We collected data on the scope of their volunteer beach cleanups, the roles they play in coordinating and conducting these cleanups, how they interact with other volunteer beach cleanups groups, and the other forms of environmental stewardship they conduct.

We define volunteer beach cleanup groups as any collective that: (1) organizes a beach cleanup for volunteers including advertising the event, recruiting volunteers, leading the cleanup on-site, and ensuring the collected litter is removed from the site; and/or (2) facilitates others' efforts to organize beach cleanups by providing a platform to advertise beach cleanup events, coordinating multi-site cleanup campaigns, and in some cases providing support materials such as step-by-step guides for organizing cleanups or online platforms for data collection. We limited our study to groups engaged in beach cleanups; groups coordinating cleanup events without a coastal focus and those groups only conducting beach litter surveys were excluded. For our sample, we aimed to strike a balance between including a wide range of group types and activities but did not attempt an exhaustive census of beach cleanup groups.

\section{Corpora}

\section{Peer-reviewed academic literature}

First, we searched peer-reviewed academic literature for mention of volunteer beach cleanups. We searched the Web of Science and ScienceDirect databases and the Cornell University Library search platform, which has access to 91 percent of the 120,000 current journal titles available online (Cornell University Library 2019). For the Web of Science search, we used the search string: (TOPIC: [beach] AND TOPIC: [clean] AND TOPIC: [volunteer]). For the ScienceDirect and Cornell University Library searches we used the search string: ("beach clean" AND volunteer) for all fields, and limited results to articles published in peerreviewed journals. We conducted these searches in July 2017 and in January 2018 and identified 215 articles; after eliminating duplicates and irrelevant articles, 81 articles remained in the corpus. In reviewing these articles, we discovered none focused on volunteer beach cleanup groups, a few addressed the practice of volunteer beach cleanups, and most mentioned volunteer beach cleanups in the context of using data on marine litter collected through volunteer beach surveys or volunteer beach cleanups. From the 81 articles, we identified the names of 62 beach cleanup groups. 


\section{Internet searches}

We identified additional beach cleanup groups through Internet searches to include groups not mentioned in the academic literature, intending to capture groups that may not have been the subject of research due to their size, geographic focus, or other unknown reasons. We conducted searches through an Internet search engine using the search strings ("beach clean":site.org) and ("limpieza de playa":site.org), and selected every third website returned by each search until we had a total of 50 group websites, 42 of which were in English and 8 in Spanish. We included groups working in Spanish contexts with the intention of increasing the potential diversity of groups and locations included in the sample. In the cases where a group selected through the Internet searches was already identified by the peer-reviewed literature search, we added the next group returned by the Internet search.

\section{Total corpus}

Of the 62 volunteer beach cleanup groups identified in the peer-reviewed literature, 30 had existing websites with information available about their beach cleaning and other activities. Groups without sufficient information to be coded in any of our four general code categories (Table 1) were excluded from the corpus. We combined these with the 50 group websites identified through the Internet searches for a total of 80 volunteer beach cleanup group websites.

\section{Coding and analysis}

We used each group's full website as the unit of analysis. We included all sub-pages within a website, but did not include links to external pages. For groups with websites and social media pages, the website was coded first, then the social media page if the information we were looking for was not found on the website. We developed four general categories of codes to identify the scope, approaches, and collaborations used by volunteer beach cleanup groups: Scope, Role of Group, Relationships to Other Volunteer Beach Cleanup Groups, and Environmental Stewardship (Table 1). The descriptive attribute codes (Saldaña 2009) in the "Scope" category were developed inductively by the first and third authors after reviewing several volunteer beach cleanup group websites. We inductively created the codes in the "Role of Group" and "Relationships" categories; these were discussed between the first and second authors. The first author used codes drawn a priori from Fisher et al.'s (2012) categories for "Other Environmental Stewardship," including management, monitoring, advocacy, and education, with the addition of a code for "research" (Table 1).

Of the 80 websites in the primary source material corpus, we stopped coding after 50 since we were not finding new combinations of coded data and had reached saturation for qualitatively describing similarities and variation between the groups based on the four general coding categories. The 50 coded websites include the 30 from the volunteer beach cleanup groups identified in the peer-reviewed literature and 20 websites from the additional groups identified through the Internet searches (see Supplementary Materials for primary source material coding). For the analysis, the first author used an iterative modified grounded theory approach (Strauss and Corbin 1997; McCreaddie and Payne 2010; Charmaz 2006) to identify emergent patterns from the data, such as the codes for "Role of group" and "Relationship." The emergent codes became apparent through the coding process, and as they became clear the first author discussed them with the second and third authors. Once agreed upon, the first author revisited previously coded primary source materials to apply the new codes.

\section{Results}

This work serves as an initial exploration aiming to describe beach cleanup groups and their practices and theorize how they may have impacts beyond local beaches, laying the groundwork for studying how civic ecology practices may be relevant for stewardship of global scale resources such as the Earth's oceans, while also gaining insight into the roles of these groups in the fight against plastic pollution.

One way volunteer beach cleanup groups could extend their impacts would be to work on scales extending beyond the local cleanup of a single beach. Over the course of coding the primary source materials (see Supplementary Materials), we identified groups working to coordinate volunteer beach cleanups at five geographic scales: local, sub-national, national, multi-national, and global. To illuminate potential differences and similarities between groups operating within the same geographic scale and across different scales, we report our findings by the coordination scale codes (Table 1). Of the 50 groups analyzed, the majority work at the subnational scale (20), followed by the national (12) and local scales (11) with fewer at the multi-national (4) and global (3) scales.

\section{Scope}

At each coordination scale, we found at least one beach cleanup organization that has been working for 17 years or more. The oldest group, Keep Wales Tidy working at the sub-national scale in the UK, has been conducting cleanups 
Table 1 Codes for scope of volunteer beach cleanup efforts, role of groups in volunteer beach cleanups, relationships between groups, and environmental stewardship activities beyond cleanups

\begin{tabular}{|c|c|c|}
\hline Category & Codes & Description \\
\hline \multirow[t]{9}{*}{ Scope } & Campaign & Name of campaign \\
\hline & Location(s) & Location(s) of most recent cleanup \\
\hline & Coordination scale & $\begin{array}{l}\text { Socio-political scale of targeted cleanup effort } \\
\text { Local (single site or municipality) } \\
\text { Sub-national (multiple sites within subsection of a country, e.g., the state of Cali- } \\
\text { fornia) } \\
\text { National (country-wide) } \\
\text { Multi-national (spanning multiple countries regionally, e.g., the Mediterranean) } \\
\text { Global (aiming to mobilize volunteers around the world) }\end{array}$ \\
\hline & First cleanup & Date of first cleanup organized by or coordinated through the group \\
\hline & Frequency & How often the cleanup occurs \\
\hline & Number of participants & Number of participants in most recently reported cleanup \\
\hline & Number of sites & Number of sites cleaned during most recently reported cleanup \\
\hline & Litter removed & $\begin{array}{l}\text { Amount of litter removed through volunteer beach cleanup, as reported by group } \\
\text { (weight, number of pieces, etc.) }\end{array}$ \\
\hline & Data collection protocol & Data collection protocol used during beach cleanup, if any \\
\hline \multirow[t]{3}{*}{ Role of group } & Coordinator & $\begin{array}{l}\text { Coordinates multiple beach cleanups through a campaign; encourages groups to } \\
\text { lead their own cleanups }\end{array}$ \\
\hline & Implementer & $\begin{array}{l}\text { Runs local cleanup; may be part of larger beach cleanup campaign or independent } \\
\text { effort }\end{array}$ \\
\hline & Coordinator and Implementer & $\begin{array}{l}\text { Runs one or several beach cleanups while also coordinating other groups or indi- } \\
\text { viduals to lead cleanups }\end{array}$ \\
\hline \multirow{3}{*}{$\begin{array}{l}\text { Relationship to other } \\
\text { volunteer beach cleanup } \\
\text { groups }\end{array}$} & Confluence & $\begin{array}{l}\text { Coordinate others' participation in their beach cleanup campaign; channel efforts of } \\
\text { tributary groups through the same initiative }\end{array}$ \\
\hline & Tributary & $\begin{array}{l}\text { Participate in beach cleanup campaigns coordinated by confluence groups. May } \\
\text { coordinate and/or implement beach cleanups separate from the confluence group's } \\
\text { campaign }\end{array}$ \\
\hline & Independent & Not connected to other volunteer beach cleanup groups or campaigns \\
\hline \multirow[t]{6}{*}{ Environmental stewardship } & Conservation & Efforts to protect, maintain, or restore an environmental area (e.g., beach cleanups) \\
\hline & Education & $\begin{array}{l}\text { Educating about the environment and environmental issues in formal or informal } \\
\text { education settings (e.g., providing educators with classroom materials to teach } \\
\text { students about plastic pollution) }\end{array}$ \\
\hline & Research & $\begin{array}{l}\text { Researching environmental issues and proposed actions (e.g., designing and } \\
\text { implementing a study of sewage outflows and plastic pollution accumulation on } \\
\text { beaches) }\end{array}$ \\
\hline & Monitoring & $\begin{array}{l}\text { Monitoring indicators of ecosystem health or other stewardship outcomes (e.g., } \\
\text { conducting regular monitoring for microplastics along beaches) }\end{array}$ \\
\hline & Advocacy & $\begin{array}{l}\text { Advocating for environmental policy or actions, at any level in the public policy } \\
\text { arena (e.g., meeting with or submitting petitions, reports or briefs to decision- } \\
\text { makers; boycotting certain plastic items, such as plastic straws or bags) }\end{array}$ \\
\hline & Management & $\begin{array}{l}\text { Managing an area for use and ecosystem health (e.g., establishing a paid service to } \\
\text { clean up beached marine debris) }\end{array}$ \\
\hline
\end{tabular}

since 1972. The newest group, Clean up Versova Beach working at the local scale in India, started in 2015. Also at each scale, there are groups holding volunteer beach cleanups multiple times during the year, ranging from Take 3's global efforts to encourage cleanups by individuals whenever they visit a beach anywhere in the world, to local groups like the Loggerhead Marine Life Center's monthly cleanups in Juno Beach, Florida (US). Groups at each scale are using protocols to collect data about the marine litter they remove.
Whereas the protocol provided by the Ocean Conservancy for their International Coastal Cleanup is the most commonly used, a number of groups in our sample use other protocols for collecting and reporting their data, making it difficult to compare measures of litter removal, numbers of participants, and numbers of sites (see Supplementary Materials).

Our corpus includes volunteer beach cleanup groups based in 15 countries (Table 2). The farthest-reaching 
Table 2 Groups and campaigns by coordination scale and country of base operations

\begin{tabular}{|c|c|c|c|}
\hline Coordination scale & Group & Campaign name & Country of base operations \\
\hline \multirow[t]{3}{*}{ Global } & Ocean conservancy & International Coastal Cleanup & US \\
\hline & Take 3: A clean beach initiative & Take 3 & Australia \\
\hline & Surfrider Foundation & Beach cleanup program & US; France; Belgium; Spain \\
\hline \multirow[t]{4}{*}{ Multi-national } & Sustainable coastlines & Sustainable Coastlines & New Zealand \\
\hline & Legambiente & Clean up the Med & Italy \\
\hline & Alliance for the Great Lakes & Adopt-a-Beach & US \\
\hline & Conservation Volunteers Australia & (various) & Australia \\
\hline \multirow[t]{12}{*}{ National } & Marine Conservation Society & Great British Beach Clean & United Kingdom (UK) \\
\hline & Tangaroa Blue Foundation & Various & Australia \\
\hline & Clean Ocean Foundation & Power Cleans & Australia \\
\hline & $\begin{array}{l}\text { World Oceans Day Canada and Oceans Week } \\
\text { Canada }\end{array}$ & World Oceans Day & Canada \\
\hline & Ocean Wise & Great Canadian Shoreline Cleanup & Canada \\
\hline & Jamaica Environment Trust & International Coastal Cleanup Day Jamaica & Jamaica \\
\hline & An Taisce & An Taisce's National Spring Clean & Ireland \\
\hline & $\begin{array}{l}\text { New Zealand Association for Environmental } \\
\text { Education }\end{array}$ & Seaweek Marine Debris Survey & New Zealand \\
\hline & Ecologistas en Acción & Limpiemos el Mar 2018 & Spain \\
\hline & Ministerio de Medio Ambiente; Chilean Navy & El día internacional de limpieza de playas & Chile \\
\hline & Mingas por el Mar & Mingas por el Mar & Ecuador \\
\hline & $\begin{array}{l}\text { US National Marine Debris Monitoring } \\
\text { Program }\end{array}$ & International Coastal Cleanup & US \\
\hline \multirow[t]{20}{*}{ Sub-national } & Asociación Ondine & Dos Manos & Spain \\
\hline & Clean Ocean Action & Beach Sweeps & US \\
\hline & Orange County Coastkeeper & (various) & US \\
\hline & Keep Wales Tidy & Be Tidy & UK \\
\hline & Sustainable Coastlines Hawaii & Sustainable Coastlines Hawaii & US \\
\hline & Forth Estuary Forum & Coastal Litter Campaign & UK \\
\hline & Norfolk Coast Partnership & Beach clean events & UK \\
\hline & https://www.volunteercleanup.org/ & (various) & US \\
\hline & Key Biscayne Community Foundation & Citizen Scientist Project & US \\
\hline & Keep Britain Tidy & BeachCare and RiverCare & UK \\
\hline & California Coastal Commission & California Coastal Day Clean Up & US \\
\hline & LOVEmyBEACH & LOVEmyBEACH & UK \\
\hline & Salem Sound Coastwatch & Coastsweep Cleanup & US \\
\hline & Plástico 0: Agüita con el plástico & Agüita con el plástico & Spain \\
\hline & National Trust & Keeping the South West coast beautiful & UK \\
\hline & EcoBarge Clean Seas Inc & Whitsunday Marine Debris Removal Program & Australia \\
\hline & Lanzarote Limpia & Lanzarote Limpia & Spain \\
\hline & Fathoms Free & Fathoms Free & UK \\
\hline & Bioagradables & Bioagradables & Spain \\
\hline & $\begin{array}{l}\text { The Georgia Sea Turtle Center Marine Debris } \\
\text { Initiative }\end{array}$ & Marine Debris Initiative & US \\
\hline
\end{tabular}


Table 2 (continued)

\begin{tabular}{|c|c|c|c|}
\hline Coordination scale & Group & Campaign name & Country of base operations \\
\hline \multirow[t]{11}{*}{ Local } & Let's Keep Hollywood Beautiful & Hollywood Beach Sweeps & US \\
\hline & I Love A Clean San Diego & Cleanups & US \\
\hline & Long Beach Water Department & Beach Clean Ups & US \\
\hline & Nature Conservancy Canada & The Great Fundy Cleanup & US \\
\hline & Loggerhead Marine Life Center & Blue Friends Beach Cleanup & US \\
\hline & Proyecto Fronterizo de Educación Ambiental & Salvemos la playa & Mexico \\
\hline & Keep Sarasota Beautiful & (various) & US \\
\hline & Friends of Baynes Sound & $\begin{array}{l}\text { Baynes Sound Cleanup (part of Great Cana- } \\
\text { dian Shoreline Cleanup) }\end{array}$ & Canada \\
\hline & Keep Lee County Beautiful, Inc & (various) & US \\
\hline & Clean up Versova Beach & Clean up Versova Beach & India \\
\hline & St. Andrew's Parish Church & Beach Clean-up & UK \\
\hline
\end{tabular}

volunteer beach cleanup is the Ocean Conservancy's global scale International Coastal Cleanup, with groups from 122 countries participating in their 2018 campaign.

\section{Roles of groups in volunteer beach cleanups}

We coded groups based on their roles in volunteer beach cleanups as either coordinators, implementers, or both. These roles varied little by coordination scale (Table 3 ). One example of a beach cleanup coordinator at the global scale is the Ocean Conservancy, which through its annual
International Coastal Cleanup campaign encourages individuals and groups to organize their own local volunteer beach cleanups as part of a global campaign. The Ocean Conservancy provides a searchable online database for local groups to post information about their cleanups so volunteers and groups can find nearby beach cleanups, resources for implementing a volunteer beach cleanup, and an app and protocol for collecting and reporting data on marine litter. The global group Take 3 uses a different coordinator model by encouraging spontaneous, asynchronous beach cleanup action by individuals rather than groups. They challenge

Table 3 Codes by coordination scale

\begin{tabular}{|l|rrrrr|r|}
\hline \multicolumn{1}{|c|}{ Code } & $\begin{array}{c}\text { Global } \\
(\mathbf{n = 3})\end{array}$ & $\begin{array}{r}\text { Multi-national } \\
(\mathbf{n = 4})\end{array}$ & $\begin{array}{c}\text { National } \\
(\mathbf{n}=\mathbf{1 1})\end{array}$ & $\begin{array}{c}\text { Sub-national } \\
(\mathbf{n}=\mathbf{2 1})\end{array}$ & $\begin{array}{c}\text { Local } \\
(\mathbf{n}=\mathbf{1 1})\end{array}$ & \multicolumn{1}{c|}{$\begin{array}{c}\text { Total } \\
(\mathbf{n}=\mathbf{5 0})\end{array}$} \\
\hline Coordinator & $2(67 \%)$ & $2(50 \%)$ & $4(36 \%)$ & $6(29 \%)$ & $0(0 \%)$ & $14(28 \%)$ \\
Implementer & $1(33 \%)$ & $1(25 \%)$ & $2(18 \%)$ & $8(38 \%)$ & $9(82 \%)$ & $21(42 \%)$ \\
Both & $0(0 \%)$ & $1(25 \%)$ & $4(36 \%)$ & $6(29 \%)$ & $2(18 \%)$ & $13(26 \%)$ \\
\hline Confluence & $1(33 \%)$ & $2(50 \%)$ & $1(9 \%)$ & $0(0 \%)$ & $0(0 \%)$ & $4(8 \%)$ \\
Tributary & $1(33 \%)$ & $1(25 \%)$ & $6(55 \%)$ & $10(48 \%)$ & $8(73 \%)$ & $26(52 \%)$ \\
Independent & $1(33 \%)$ & $1(25 \%)$ & $2(18 \%)$ & $2(10 \%)$ & $3(27 \%)$ & $7(14 \%)$ \\
\hline Conservation & $3(100 \%)$ & $4(100 \%)$ & $11(100 \%)$ & $21(100 \%)$ & $11(100 \%)$ & $50(100 \%)$ \\
Education & $3(100 \%)$ & $4(100 \%)$ & $10(91 \%)$ & $21(100 \%)$ & $8(73 \%)$ & $46(92 \%)$ \\
Research & $1(33 \%)$ & $2(50 \%)$ & $6(55 \%)$ & $11(52 \%)$ & $3(27 \%)$ & $23(46 \%)$ \\
Monitoring & $1(33 \%)$ & $2(50 \%)$ & $7(64 \%)$ & $12(57 \%)$ & $4(36 \%)$ & $26(52 \%)$ \\
Policy advocacy & $2(67 \%)$ & $2(50 \%)$ & $6(55 \%)$ & $10(48 \%)$ & $4(36 \%)$ & $24(48 \%)$ \\
\hline Management & $0(0 \%)$ & $0(0 \%)$ & $2(18 \%)$ & $5(24 \%)$ & $4(36 \%)$ & $11(22 \%)$ \\
\hline
\end{tabular}

Gray scale reflects percent of groups coded per coordination scale (0-24.9\%: white; $25-49.9 \%$ : light gray; 50-74.9\%: gray; $75-100 \%$ : dark gray) 
beach-goers to pick up three pieces of marine litter each time they go to the beach and post a photograph of the litter on Instagram. Alternatively, Surfrider Foundation, in their global implementer role, conducts beach cleanups via their own local volunteer chapters around the world. Tangaroa Blue Foundation is both coordinator and implementer at the national level across Australia. They coordinate beach cleanups by providing guides and other resources for individuals and communities to run their own cleanups and also implement volunteer beach cleanups throughout the year.

\section{Relationships between volunteer beach cleanup groups}

Through the emergent codes for relationships between volunteer beach cleanup groups, we identified: (1) confluence groups, which lead campaigns in which other groups are encouraged to participate; (2) tributary groups, which participate in campaigns led by confluence groups; and iii) independent groups, which work separately from other volunteer beach cleanup groups. Confluence groups were identified within the national, multi-national, and global scales; tributary groups at all scales; and independent groups at all scales except for the global (Table 3). Legambiente is a multi-national confluence group that has led the "Clean Up the Med" campaign since 1995. Similar to the Ocean Conservancy's International Coastal Cleanup, Legambiente encourages schools, institutions, and local communities from any country bordering the Mediterranean Sea to participate by organizing their own beach cleanups as part of the Mediterranean-scale Clean Up the Med campaign. They ask groups to collect data on the litter they remove during the beach cleanup and send their data to the Clean Up the Med organizers. Surfrider Foundation is an example of a tributary group operating at the global scale by participating in the Ocean Conservancy's International Coastal Cleanup. Another tributary group, Clean Ocean Action (New Jersey, US), operates at the sub-national scale and coordinates and implements two major volunteer beach cleanup campaigns annually, one of which is part of the International Coastal Cleanup. Lanzarote Limpia (Canary Islands, Spain) is a sub-national, independent volunteer beach cleanup group conducting its own cleanups monthly throughout the year without participating in other groups' campaigns.

\section{Environmental stewardship}

In order for groups to be considered in our sample, they needed to be involved in the environmental stewardship practice of volunteer beach cleanups, either as coordinators, implementers, or both. This means all groups at all scales in this analysis conduct conservation as one type of environmental stewardship. Across all groups in our sample, education is the most common form of additional environmental stewardship, and management is the least common. At all coordination scales, groups conduct education, advocacy, research, and monitoring. For example, at the national scale, the Marine Conservation Society (UK) uses their website as a platform for promoting beach cleanup campaigns such as their Great British Beach Clean, and they provide space and materials for volunteers interested in joining or organizing a beach cleanup. They post educational information about ocean conservation concerns, including marine litter, and conduct research and monitoring on water quality and marine litter. They also advocate for changing UK policy, such as their successful effort to get the UK government to impose a charge for single-use shopping bags in English shops (Marine Conservation Society 2019). At the sub-national level, the "Plástico 0: Agüita con el plástico" campaign on the island of Lanzarote (Canary Islands, Spain) conducts ongoing research and monitoring for microplastics in collaboration with local schools, where education modules on marine litter have been integrated into the curriculum. Additionally, they work with local businesses to eliminate single-use plastics such as shopping bags.

Some groups operating at the local, sub-national, or national scales conduct management, as they own or have decision-making control over a coastal area. For example, the local Long Beach Water Department (California, USA) has managerial responsibility for Bluff Park Beach. They integrate an annual volunteer beach cleanup with education and outreach efforts. Their cleanup is a tributary to the subnational California Coastal Cleanup Day campaign, which in turn contributes to the International Coastal Cleanup. They also conduct water quality monitoring and research, and advocate for water conservation. At the local, sub-national, and national scales, there are groups conducting all forms of environmental stewardship (Table 3).

\section{Discussion}

As plastic pollution increases the world over, volunteer beach cleanups have become a common local response to this global challenge. Our exploratory content analysis of primary source materials produced by volunteer beach cleanup groups allowed us to compile a descriptive overview of the scope of these groups' beach cleanup efforts, the ways in which they relate to each other, and the other kinds of environmental stewardship they conduct. Here, we address the theoretical implications of our findings by connecting the emergent patterns with Krasny's (2018) theory on the three pathways civic ecology practices follow to achieve broader impacts through knowledge-, culture-, and movement building. 


\section{Knowledge building}

Volunteer beach cleanup groups in this study conduct monitoring, research, and education as mechanisms for branching out their impact through the pathway of knowledge building (Krasny 2018, Supplementary Materials). Furthermore, our review of the academic literature found scholars use data collected by volunteers participating in beach surveys and beach cleanups (Bergmann et al. 2017; Wyles et al. 2016; Kordella et al. 2010; Ribic et al. 1997; Pearce 1992). Groups such as the Ocean Conservancy provide volunteers with data collection protocols through computer platforms or smartphone applications (see Supplementary Materials). The data collected through these platforms spike during major cleanup events, such as the International Coastal Cleanup in September, but data are also reported periodically on a smaller scale by spontaneous local beach cleanups such as those encouraged by Take 3, or cleanups occurring regularly throughout the year such as those facilitated by Sustainable Coastlines Hawaii. However, we found a variety of data reporting conventions between different groups (see Supplementary Materials), and suggest beach cleanup groups standardize their data collection protocols and reporting conventions to enhance their contributions to knowledge building about plastic pollution.

Knowledge building by the volunteer beach cleanup groups in our study also occurs through conservation and management stewardship practices, which involve creating and sharing tacit knowledge (Silva 2017) about marine litter and the practice of volunteer beach cleaning. For example, Tangaroa Blue Foundation codifies knowledge gained through its experience coordinating and implementing beach cleanups in the protocols and how-to materials they provide to those interested in participating in their campaigns or organizing a cleanup. By learning through doing and sharing these lessons openly, these groups contribute to knowledge building about best practices for volunteer beach cleanups. Their data tracking platforms and databases also can be drawn upon to inform plastic pollution governance at various scales as they provide snapshots of where and when marine litter accumulates.

\section{Culture building}

Volunteer beach cleanup groups may foster culture building by setting norms for taking action against plastic pollution, particularly by showing groups already acting (Cialdini et al. 1991; Schultz et al. 2007; Nolan et al. 2008). For example, in our sample, we found cleanup coordinators using multiplicative strategies (Edwards and Hulme 2002) to scale up their impacts by catalyzing others to lead their own cleanups. They do this by sharing how-to guides, data collection protocols, online platforms announcing cleanup activities, and, for beach cleanup implementers, by leading through example in their own cleanup efforts. Environmental management stewardship activities may also contribute to culture building, given that management decisions reflect social values within the conditions of a given context (Ives and Kendal 2014). Further, the act of volunteering to clean a beach performatively enacts cultural values (Butler 2010) related to conservation. Culture building may also occur as participants develop a supportive social context for the act of picking up garbage. Studies exploring normative social influence on environmental behavior have demonstrated the powerful influence of witnessing the actions of others (Nolan et al. 2008), and while we did not measure this directly in our study, our results support Nolan et al.'s (2008) finding that such influence can be exerted through first-hand experience as well as through communications about the behavior, such as the stories posted by volunteer beach cleanup groups on their webpages.

\section{Movement building}

Movement building may be indicated by the environmental stewardship practice of advocacy, as advocacy entails building a base of support among the public to pressure policy-makers and businesses regarding a particular cause (Handy 2001). For example, we found volunteer beach cleanup groups conducting advocacy for federal marine litter policies (e.g., Marine Conservation Society [UK], the Ocean Conservancy [US], Clean Ocean Foundation [Australia], the Tangaroa Blue Foundation). Another example of movement building by a beach cleanup group can be seen in the efforts of Proyecto Fronterizo de Educación Ambiental (Mexico), which facilitates a civic participation council that brings together the public and managers of the Río Tijuana watershed. This suggests an example of the polycentric governance advocated for by Ostrom (2010). In all cases from our sample, groups conducting advocacy also conduct stewardship through education, and the majority are conducting research and/or monitoring. As such, our findings suggest that movement building within the context of volunteer beach cleanups is related to knowledge- and culture-building practices of environmental stewardship. This allows us to elaborate on Krasny's (2018) pathways theory to suggest that the pathways of culture building and knowledge building can lead to movement building.

In terms of movement building through stewardship governance networks (Gunderson et al. 2018), our findings demonstrate that local-scale volunteer beach cleanup groups form vertical partnerships with sub-national, national, multinational, and global campaigns. The extent of networking with the potential to create a global, synchronized civic ecology practice is more pronounced in litter cleanups relative to other civic ecology practices (Krasny and Tidball 2015; 
Krasny 2018). This is made possible in part through connective action, or Internet-enabled organizing through flexible associations with groups or campaigns for a particular cause (Bennett and Segerberg 2013).

While the robustness of these beach cleanup networks has not been documented, their existence merits further investigation to understand their role in global plastic pollution governance. As Loges and Jakobi (2019) argue, current plastic governance is "an incoherent mosaic of simultaneous processes by various actors" that needs to become more integrated and effective through actors sharing common understandings of "central problems, relevant values and appropriate behavior" (p. 15). Local beach cleanups coming together and becoming tributaries to larger campaigns is consistent with what Oliver and Myers (2003) see as a requirement for social action, i.e., individuals coming together create collective actors, which in turn unite to create larger collective actors. Understanding existing networks of beach cleanup groups could help in creating coherent yet polycentric plastic governance systems, allowing experimentation and learning as diverse policies are implemented and information is shared through networks spanning multiple scales (Ostrom 2010).

While more policies are being passed aiming to address plastic pollution at various scales (Xanthos and Walker 2017), these efforts are falling short of what is needed to address the root causes of plastic pollution globally, driven by the continued increase in plastic production (PlasticsEurope 2019). Our findings suggest volunteer beach cleanup groups are contributing to building the movement against plastic pollution, but more steps are needed.

\section{Limitations}

This study lays groundwork for understanding the ways in which practices of environmental stewardship groups can cause ripple effects that end up spanning oceans. As an exploratory content analysis of primary source material from volunteer beach cleanup groups, our study is limited in its capacity to verify groups' activities and their direct impacts; instead, we engage at a theoretical level with how the environmental stewardship practices and relationships between groups indicated in the primary source materials connect with theories about how civic ecology practices and collective action scale up into polycentric environmental governance. We also recognize our sample size of 50 may not be representative of the full spectrum of volunteer beach cleanup groups. However, for our purposes, it is sufficient to demonstrate that volunteer beach cleanup groups operate at scales ranging from local to global, that within each scale groups conduct varying kinds of environmental stewardship, that these groups may perform the role of coordinator, implementer, or both in the beach cleanup practices they promote, and some groups are linked to others by participating in their beach cleanup campaigns.

\section{Conclusion}

A single thread is a fragile thing, but blended with other fibers and woven with other strands the resulting net can become robust. Our study reveals a rudimentary tapestry telling the story of how volunteer beach cleanup groups work to branch out and scale up their impacts by combining different forms of plastic pollution-related environmental stewardship, bringing together members of civil society, and collaborating with other groups as part of a growing social movement against plastic pollution reaching the global scale. Our results indicate some volunteer beach cleanup groups using multiple strategies for tackling plastic pollution, branching out by conducting various forms of environmental stewardship. Through volunteer beach cleanups, community members learn first hand about local plastic pollution. By documenting their findings, groups create and share new knowledge. Volunteer beach cleanup coordinator groups weave networks of local participants by providing platforms and materials for those interested in conducting cleanups independently or as part of a larger campaign. Volunteer beach cleanup implementers lead by example, enabling social learning among participants about how and why to conduct cleanups. Tributary groups strengthen larger campaigns led by confluence groups, which integrate diffuse initiatives ranging from the local to the global. In this way, we see volunteer beach cleanup groups do more to address global plastic pollution than simply clean beaches. They weave together diverse forms of environmental stewardship, potentially broadening their impacts through knowledge-, culture-, and movement building, and collaborate across scales to form a network of ocean stewardship groups. Alongside these efforts, and to prevent their co-option into "busy-ness" (MacBride 2011), volunteer beach cleanup groups and others also need to hold industry accountable for preventing the flow of plastics into the environment.

Acknowledgements We thank the anonymous reviewers whose comments, suggestions, and encouragement greatly improved this manuscript.

Funding Funding was provided by National Institute of Food and Agriculture (NYC-147859).

\section{References}

Abhyankar A, Krasny ME (2018) From practice to fledgling social movement in India: lessons from the Ugly Indian. In: Krasny ME 
(ed) Grassroots to global: broader impacts of civic ecology. Cornell University Press, Ithaca, pp 231-248

Andrews K, Edwards B (2005) The organizational structure of local environmentalism. Mobil Int Q 10(2):213-234

Barnes DKA, Galgani F, Thompson RC, Barlaz M (2009) Accumulation and fragmentation of plastic debris in global environments. Philos Trans R Soc B Biol Sci 364:1985-1998

Baztan J, Jorgensen B, Pahl S, Thompson RC, Vanderlinden J-P (eds) (2016) MICRO 2016: fate and impact of microplastics in marine ecosystems: from the coastline to the open sea. Elsevier, New York

Baztan J, Bergmann M, Booth A, Broglio E, Carrasco A, Chouinard O, Clüsener-Godt M, Cordier M, Cozar A, Devrieses L, Enevoldsen $\mathrm{H}$ et al (2017) Breaking down the plastic age. In: Baztan J, Jorgensen B, Pahl S, Thompson RC, Vanderlinden J-P (eds) MICRO 2016: fate and impact of microplastics in marine ecosystems. Elsevier, pp 177-181

Baztan J, Bergmann M, Carrasco A, Fossi C, Jorgensen B, Miguelez Q, Pahl S, Thompson RC, Vanderlinden JP (eds) (2018) MICRO 2018. Fate and impact of microplastics: knowledge, actions and solutions. MSFS-RBLZ, CC-BY-NC-SA, e-ISBN 978-84-09-06477-9

Benford RD, Snow DA (2000) Framing processes and social movements: an overview and assessment. Ann Rev Sociol 26(1):611-639

Bennett WL, Segerberg A (2013) The logic of connective action: digital media and the personalization of contentious politics. Cambridge University Press, Cambridge

Bennett NJ, Whitty TS, Finkbeiner E, Pittman J, Bassett H, Gelcich S, Allison EH (2018) Environmental stewardship: a conceptual review and analytical framework. Environ Manag 61(4):597-614

Bergmann MB, Lutz B, Tekmaz MB, Gutow L (2017) Citizen scientists reveal: marine litter pollutes arctic beaches and affects wild life. Mar Pollut Bull 125(1-2):535-540

Bergmann M, Mützel S, Primpke S, Tekman MB, Trachsel J, Gerdts G (2019) White and wonderful? Microplastics prevail in snow from the Alps to the Arctic. Sci Adv 5(8):eaax 1157

Braun YA, Traore AS (2015) Plastic bags, pollution, and identity: women and the gendering of globalization and environmental responsibility in Mali. Gend Soc 29(6):863-887

Butler J (2010) Performative agency. J Cult Econ 3(2):147-161

Chan J, DuBois B, Tidball KG (2015) Refuges of local resilience: community gardens in post-Sandy New York City. Urban For Urban Green 14(3):625-635

Chapin FS III, Power ME, Pickett ST, Freitag A, Reynolds JA, Jackson RB, Bartuska A (2011) Earth stewardship: science for action to sustain the human earth system. Ecosphere 2(8):1-20

Charmaz K (2006) Constructing grounded theory: a practical guide through qualitative analysis. Sage, London

Chaves M, Wals AE (2018) The nature of transformative learning for social-ecological sustainability. In: Krasny M (ed) Grassroots to global: broader impacts of civic ecology. Cornell University Press, Ithaca, pp 105-123

Cialdini RB, Kallgren CA, Reno RR (1991) A focus theory of normative conduct: a theoretical refinement and reevaluation of the role of norms in human behavior. Adv Exp Soc Psychol 24:201-234

Connolly JJ, Svendsen ES, Fisher DR, Campbell LK (2014) Networked governance and the management of ecosystem services: the case of urban environmental stewardship in New York City. Ecosyst Serv 10:187-194

Cornell University Library (2019) Collections. https://www.libra ry.cornell.edu/about/collections. Accessed 27 Jan 2019

Cózar A, Echevarría F, González-Gordillo JI, Irigoien X, Úbeda B, Hernández-León S, Fernández-de-Puelles ML (2014) Plastic debris in the open ocean. Proc Natl Acad Sci 111(28):10239-10244
De Wolff K (2017) Plastic naturecultures: multispecies ethnography and the dangers of separating living from nonliving bodies. Body Soc 23(3):23-47

Derraik JG (2002) The pollution of the marine environment by plastic debris: a review. Mar Pollut Bull 44(9):842-852

Douglas M (2003) Purity and danger: an analysis of concepts of pollution and taboo. Routledge, London

Edwards M, Hulme D (2002) Making a difference: scaling-up the developmental impact of NGOs-Concepts and experiences. In: Edwards M, Fowler A (eds) The Earthscan reader on NGO management. Earthscan Publications Ltd, London

Elmore BJ (2014) Citizen coke: the making of coca-cola capitalism. WW Norton \& Company, New York

Enqvist JP, Campbell LK, Stedman RC, Svendsen ES (2019) Place meanings on the urban waterfront: a typology of stewardships. Sustain Sci 14(3):589-605

Fisher DR, Campbell LK, Svendsen ES (2012) The organisational structure of urban environmental stewardship. Environ Politics 21(1):26-48

Fisher DR, Svendsen ES, Connolly JJ (2015) Urban environmental stewardship and civic engagement: how planting trees strengthens the roots of democracy. Routledge, Abingdon

Folke C, Jansson $\AA$, Rockström J, Olsson P, Carpenter SR, Chapin FS, Crépin AS, Daily G, Danell K, Ebbesson J, Elmqvist T (2011) Reconnecting to the biosphere. Ambio 40(7):719-738

Galgani F, Hanke G, Maes T (2015) Global distribution, composition and abundance of marine litter. In: Bergmann M, Gutow L, Klages M (eds) Marine anthropogenic litter. Springer, Cham, pp 29-56

Gunderson L, Pierce EW, Krasny ME (2018) Adaptive management, adaptive governance, and civic ecology. In: Krasny M (ed) Grassroots to global: broader impacts of civic ecology. Cornell University Press, Ithaca, pp 157-176

Handy F (2001) Advocacy by environmental nonprofit organisations: an optimal strategy for addressing environmental problems? Int J Soc Econ 28(8):648-666

Harvey F (2019) Industry alliance sets out \$1bn to tackle oceans' plastic waste. The Guardian. https://www.theguardian.com/envir onment/2019/jan/16/industry-alliance-sets-out-1bn-to-tackl e-oceans-plastic-waste. Accessed 27 July 2019

Hawkins G (2006) The ethics of waste: how we relate to rubbish. Rowman \& Littlefield, Lanham

Haywood BK, Parrish JK, Dolliver J (2016) Place-based and data-rich citizen science as a precursor for conservation action. Conserv Biol 30(3):476-486

Henderson L, Green C (2020) Making sense of microplastics? Public understandings of plastic pollution. Mar Pollut Bull 1(152): 110908

Ives CD, Kendal D (2014) The role of social values in the management of ecological systems. J Environ Manag 144:67-72

Jagers SC, Harring N, Löfgren Å, Sjöstedt M, Alpizar F, Brülde B, Steffen W (2019) On the preconditions for large-scale collective action. Ambio 12:1-5

Jambeck JR, Geyer R, Wilcox C, Siegler TR, Perryman M, Andrady A, Law KL (2015) Plastic waste inputs from land into the ocean. Science 347(6223):768-771

Kassam KA, Golshani Z, Krasny ME (2018) Grassroots stewardship in Iran: the rise and significance of nature cleaners. In: Krasny M (ed) Grassroots to global: broader impacts of civic ecology. Cornell University Press, Ithaca, pp 65-84

Kempton W, Holland DC, Bunting-Howarth K, Hannan E, Payne C (2001) Local environmental groups: a systematic enumeration in two geographical areas. Rural Sociol 66(4):557-578

Kistler A, Muffett C (2019) Plastic \& climate: the hidden costs of a plastic planet. Center for International Environmental Law. www. ciel.org/plasticandclimate 
Kordella S, Papatheodorou G, Geraga M, Fakiris E, Mitropoulou A, Network MS (2010) Litter composition and source identification for 80 beaches in Greece. Rapport Commission International Mer Méditerranée 39:764

Krasny ME (2018) Grassroots to global: broader impacts of civic ecology. Cornell University Press, Ithaca

Krasny ME, Tidball KG (2012) Civic ecology: a pathway for earth stewardship in cities. Front Ecol Environ 10(5):267-273

Krasny ME, Tidball KG (2015) Civic ecology: adaptation and transformation from the ground up. MIT Press, Cambridge

Lavers JL, Bond AL (2017) Exceptional and rapid accumulation of anthropogenic debris on one of the world's most remote and pristine islands. Proc Natl Acad Sci 114(23):6052-6055

Laville S (2019) Founders of plastic waste alliance 'investing billions in new plants'. The Guardian, Retrieved from: https://www. theguardian.com/environment/2019/jan/21/founders-of-plast ic-waste-alliance-investing-billions-in-new-plants. Accessed 27 July 2019

Law KL, Thompson RC (2014) Microplastics in the seas. Science 345:144-145

Let's Do It! Foundation (2018) World cleanup day 201815 Sept infographic. https://www.letsdoitworld.org/wp-content/uploa ds/2019/02/WCD-Results-infographic-15.10.18.jpg. Accessed 25 July 2019

Littler J (2013) What's wrong with ethical consumption? In: Lewis T, Potter E (eds) Ethical consumption: an introduction. Routledge, London, pp 27-39

Loges B, Jakobi AP (2019) Not more than the sum of its parts: decentered norm dynamics and the governance of plastics. Environ Politics 15:1-20

MacBride S (2011) Recycling reconsidered: the present failure and future promise of environmental action in the United States. MIT Press, Cambridge

Marine Conservation Society (2019) Our successes. https://www. mcsuk.org/who-we-are/our-successes. Accessed 23 Nov 2019

McCreaddie M, Payne S (2010) Evolving grounded theory methodology: towards a discursive approach. Int J Nurs Stud 47(6):781-793

Murphy A, Enqvist JP, Tengö M (2019) Place-making to transform urban social-ecological systems: insights from the stewardship of urban lakes in Bangalore. India Sustain Sci 14(3):607-623

Nelms S, Coombes C, Foster L, Galloway T, Godley B, Lindeque P, Witt M (2016) Marine anthropogenic litter on British beaches: a 10-year nationwide assessment using citizen science data. Sci Total Environ 579:1399-1409

Newman S, Watkins E, Farmer A, Ten Brink P, Schweitzer JP (2015) The economics of marine litter. In: Bergmann M, Gutow L, Klages M (eds) Marine anthropogenic litter. Springer, Cham, pp 367-394

Nilsson A, Bergquist M, Schultz PW (2017) Spillover effects in environmental behaviors, across time and context: a review and research agenda. Environ Educ Res 23(4):573-589

Nolan JM, Schultz PW, Cialdini RB, Goldstein NJ, Griskevicius V (2008) Normative social influence is underdetected. Pers Soc Psychol Bull 34(7):913-923

Ocean Conservancy (2019) The beach and beyond 2019 report. https:// oceanconservancy.org/trash-free-seas/international-coastal-clean up/annual-data-release/. Accessed 23 Nov 2019

Ogden L, Heynen N, Oslender U, West P, Kassam KA, Robbins P (2013) Global assemblages, resilience, and Earth Stewardship in the Anthropocene. Front Ecol Environ 11(7):341-347

Oliver PE, Myers DJ (2003) Networks, diffusion, and cycles of collective action. In: Social movements and networks: relational approaches to collective action. Oxford University Press, pp 173-203

Ostrom E (2010) Beyond markets and states: polycentric governance of complex economic systems. Am Econ Rev 100(3):641-672
Ostrom V, Tiebout CM, Warren R (1961) The organization of government in metropolitan areas: a theoretical inquiry. Am Political Sci Rev 55(4):831-842

Pearce JB (1992) Marine vessel debris: a North American perspective. Mar Pollut Bull 24(12):586-592

PlasticsEurope (2019) Plastics-the facts 2019: an analysis of European plastics production, demand and waste data. https://www. plasticseurope.org/en/resources/publications/1804-plastics-facts -2019. Accesssed 15 Mar 2020

Power ME, Chapin FS III (2009) Planetary stewardship. Front Ecol Environ 7(8):399-399

Rees G, Pond K (1995) Marine litter monitoring programmes: a review of methods with special reference to national surveys. Elsevier, Oxford

Ribic CA, Johnson SW, Cole CA (1997) Distribution, type, accumulation, and source of marine debris in the United States, 1989-1993. Marine debris. Springer, New York, pp 35-47

Rogers H (2009) Garbage capitalism's green commerce. Soc Regist 43:231-253

Romolini M, Grove JM, Locke DH (2013) Assessing and comparing relationships between urban environmental stewardship networks and land cover in Baltimore and Seattle. Lands Urban Plan 120:190-207

Romolini M, Grove JM, Ventriss CL, Koliba CJ, Krymkowski DH (2016) Toward an understanding of citywide urban environmental governance: an examination of stewardship networks in Baltimore and Seattle. Environ Manag 58(2):254-267

Saldaña J (2009) The coding manual for qualitative researchers. Sage Publications Ltd, London

Schultz PW, Nolan JM, Cialdini RB, Goldstein NJ, Griskevicius V (2007) The constructive, destructive, and reconstructive power of social norms. Psychol Sci 18(5):429-434

Silva P (2017) Knowledge from data, knowledge from doing: the inclusionary production of environmental knowledge for management. ProQuest Information and Learning, Ann Arbor. https://hdl.handl e.net/1813/51624. Accessed 25 July 2019

Silva P, Krasny ME (2016) Parsing participation: models of engagement for outcomes monitoring in urban stewardship. Local Environ 21(2):157-165

Silva P, Ramirez RL (2018) Making knowledge in civic ecology practices. In: Krasny ME (ed) Grassroots to global: broader impacts of civic ecology. Cornell University Press, Ithaca, pp 124-154

Smith JG, DuBois B, Krasny ME (2016) Framing for resilience through social learning: impacts of environmental stewardship on youth in post-disturbance communities. Sustain Sci 11(3):441-453

Stafford R, Jones PJS (2019) Viewpoint-ocean plastic pollution: a convenient but distracting truth? Mar Policy 103:187-191

Steffen W, Persson A, Deutsch L, Zalasiewicz J, Williams M, Richardson K, Molina M (2011) The Anthropocene: from global change to planetary stewardship. Ambio 40(7):739

Strauss A, Corbin JM (1997) Grounded theory in practice. Sage, Cham

Svendsen ES, Campbell LK (2008) Urban ecological stewardship: understanding the structure, function and network of communitybased urban land management. Cities Environ 1(1):4-31

Svendsen ES, Campbell LK, Fisher DR, Connolly JJ, Johnson ML, Sonti NF, Romolini, M (2016) Stewardship mapping and assessment project: a framework for understanding community-based environmental stewardship. US Department of Agriculture, Forest Service, Northern Research Station, General Technical Report NRS-156

Thøgersen J, Crompton T (2009) Simple and painless? The limitations of spillover in environmental campaigning. J Consum Policy 32(2):141-163

Topçu EN, Tonay AM, Dede A, Öztürk AA, Öztürk B (2013) Origin and abundance of marine litter along sandy beaches of the Turkish Western Black Sea Coast. Mar Environ Res 85:21-28 
Thiel M, Hinojosa IA, Miranda L, Pantoja JF, Rivadeneira MM, Vásquez N (2013) Anthropogenic marine debris in the coastal environment: a multi-year comparison between coastal waters and local shores. Mar Pollut Bull 71(1-2):307-316

Thompson RC, Moore CJ, Vom Saal FS, Swan SH (2009) Plastics, the environment and human health: current consensus and future trends. Philos Trans R Soc Lond B Biol Sci 364(1526):2153-2166

UNEP \& GRID-Arendal (2016) Marine Litter Vital Graphics. United Nations Environment Programme and GRID-Arendal. https:// www.grida.no/publications/60. Accessed $10 \mathrm{Feb} 2019$

Van Sebille E, Wilcox C, Lebreton L, Maximenko N, Hardesty BD, Van Franeker JA, Law KL (2015) A global inventory of small floating plastic debris. Environ Res Lett 10(12):124006

Wagner M, Lambert S, Lambert MW (2018) Freshwater microplastics. Springer, Cham

Wenger E, McDermott RA, Snyder W (2002) Cultivating communities of practice: a guide to managing knowledge. Harvard Business Press, Harvard
Williams AT, Randerson P, DiGiacomo C, Anfuso G, Macias A, Perales JA (2016) Distribution of beach litter along the coastline of Cádiz, Spain. Mar Pollut Bull 107(1):77-87

Wolf KL, Blahna DJ, Brinkley W, Romolini M (2013) Environmental stewardship footprint research: linking human agency and ecosystem health in the Puget Sound region. Urban Ecosyst 16(1):13-32

Wyles K, Pahl S, Holland M, Thompson R (2016) Can beach cleans do more than clean-up litter? Comparing beach cleans to other coastal activities. Environ Behav 49(5):509-535

Xanthos D, Walker TR (2017) International policies to reduce plastic marine pollution from single-use plastics (plastic bags and microbeads): a review. Mar Pollut Bull 118:17-26

Publisher's Note Springer Nature remains neutral with regard to jurisdictional claims in published maps and institutional affiliations. 